\title{
Forecasting of cyclone Viyaru and Phailin by NWP-based cyclone prediction system (CPS) of IMD - an evaluation
}

\author{
S D Kotal ${ }^{1}$, S K Bhattacharya, ${ }^{1, *}$ S K Roy Bhowmik ${ }^{1}$ and P K Kundu 2 \\ ${ }^{1}$ India Meteorological Department, NWP Division, New Delhi 110 003, India. \\ ${ }^{2}$ Department of Mathematics, Jadavpur University, Kolkata 700 032, India. \\ ${ }^{*}$ Corresponding author.e-mail: sumit.kumar.bhattacharya@gmail.com
}

An objective NWP-based cyclone prediction system (CPS) was implemented for the operational cyclone forecasting work over the Indian seas. The method comprises of five forecast components, namely (a) Cyclone Genesis Potential Parameter (GPP), (b) Multi-Model Ensemble (MME) technique for cyclone track prediction, (c) cyclone intensity prediction, (d) rapid intensification, and (e) predicting decaying intensity after the landfall. GPP is derived based on dynamical and thermodynamical parameters from the model output of IMD operational Global Forecast System. The MME technique for the cyclone track prediction is based on multiple linear regression technique. The predictor selected for the MME are forecast latitude and longitude positions of cyclone at 12-hr intervals up to 120 hours forecasts from five NWP models namely, IMD-GFS, IMD-WRF, NCEP-GFS, UKMO, and JMA. A statistical cyclone intensity prediction (SCIP) model for predicting 12 hourly cyclone intensity (up to 72 hours) is developed applying multiple linear regression technique. Various dynamical and thermodynamical parameters as predictors are derived from the model outputs of IMD operational Global Forecast System and these parameters are also used for the prediction of rapid intensification. For forecast of inland wind after the landfall of a cyclone, an empirical technique is developed. This paper briefly describes the forecast system CPS and evaluates the performance skill for two recent cyclones Viyaru (non-intensifying) and Phailin (rapid intensifying), converse in nature in terms of track and intensity formed over Bay of Bengal in 2013. The evaluation of performance shows that the GPP analysis at early stages of development of a low pressure system indicated the potential of the system for further intensification. The 12-hourly track forecast by MME, intensity forecast by SCIP model, and rapid intensification forecasts are found to be consistent and very useful to the operational forecasters. The error statistics of the decay model shows that the model was able to predict the decaying intensity after landfall with reasonable accuracy. The performance statistics demonstrates the potential of the system for improving operational cyclone forecast service over the Indian seas.

\section{Introduction}

India Meteorological Department (IMD) has the responsibility of forecasting tropical cyclone (TC) over the Indian seas. For all operationally designated tropical cyclones in the Indian seas, the
IMD issues an official forecast of the cyclone track (centre of location) and intensity based on synoptic and numerical model guidance. In view of disastrous impact over densely populated coastal area surrounding the North Indian Ocean (NIO), accurate forecasting of tropical cyclone (TC) has been

Keywords. Cyclone genesis potential parameter (GPP); Multi-Model Ensemble (MME) technique; cyclone track and intensity prediction; rapid intensification; decay. 
a great challenge to the operational forecasters. Forecasting tropical cyclone involves real time forecasting of genesis, track, landfall, intensity, rapid intensification, and decay after landfall. The outputs of NWP models are not uniform. Therefore, there are bound to be wide variations in predictions of track and landfall point of any system. To deal with the limitations, many studies (Krishnamurti et al. 1999, 2000; Goerss 2000; Mackey and Krishnamurti 2001; Weber 2003; Williford et al. 2003) showed that adoption of ensemble technique could be a useful option for operational forecasting. Kotal and Roy Bhowmik (2011) showed that Multi-Model Ensemble (MME) improved the forecast skill of tropical cyclone track over the member models for the NIO.

Prediction of intensity as well as decay after landfall has still been a concern to the forecasters and researchers.DeMaria and Kaplan (1994) developed a Statistical Hurricane Intensity Prediction Scheme (SHIP) for the prediction of hurricane intensity over Atlantic. Subsequently, SHIP model was updated (DeMaria and Kaplan 1999) and further updatedby DeMaria et al. (2005). Fitzpatrick (1997) developed Typhoon Intensity Prediction Scheme for understanding and forecasting TC intensity. Roy Bhowmik et al. (2007) proposed an empirical model for predicting intensity of TCs over Bay of Bengal based on observed intensity data. Kotal et al. (2008) developed a SCIP model for the prediction of TC intensity over Bay of Bengal.

The nature of decay of TCs after landfall is a major concern, as entering into the land it causes massive destruction to life and property. Kaplan and DeMaria $(1995,2001)$ developed an empirical model for predicting intensity of hurricanes crossing coastal areas of the United States. Kalsi et al. (2003) studied the decay of the Orissa Super cyclone (1999). Roy Bhowmik et al. (2005) put forth an empirical formula to predict decay after landfall over the Indian region.

As part of the effort to meet the need of the operational forecaster, an NWP-based objective Cyclone Prediction System (CPS) is developed and implemented for the operational cyclone forecasting work. The method comprises of five forecast components, namely (a) cyclone genesis potential parameter (GPP), (b) Multi-Model Ensemble (MME) technique for cyclone track prediction, (c) cyclone intensity prediction (SCIP), (d) rapid intensification, and (e) predicting decaying intensity after the landfall. GPP is used to identify the potential cyclogenesis zone and also to understand the potential of cyclogenesis of a low pressure system (Kotal et al. 2009; Kotal and Bhattacharya 2013). An MME forecast of NWP models is generated in real time for predicting the track of tropical cyclones over the Indian seas using the outputs of member models IMD-GFS, IMD-WRF, NCEPGFS, UKMO, and JMA (Kotal and Roy Bhowmik 2011). SCIP model is run for intensity predictions at 12-hr intervals up to 72 hours (Kotal et al. 2008). A rapid intensification index (RII) is used for the probability forecast of rapid intensification (RI) (Kotal and Roy Bhowmik 2013). A decay model has been used for real time forecasting of decaying intensity after the landfall (Roy Bhowmik et al. 2005).

The tropical cyclone Viyaru maintained a quasiuniform intensity during its life time. Despite traveling about $2150 \mathrm{~km}$ in more than 120 hours over the sea, the cyclonic storm (CS) intensity, once attained, did not intensify further. The course of movement of the system was also recurved towards northeast direction (crossing southeast Bangladesh). On the contrary, the cyclone Phailin over the Bay of Bengal intensified into a very severe cyclonic storm and also experienced rapid intensification phase (intensity increased by $30 \mathrm{kt}$ or more during the subsequent 24 hours (Kotal et al. 2012)) during its lifetime and reached maximum intensity up to $115 \mathrm{kt}$. The system moved in the northwest direction and crossed Gopalpur (Odisha).

This paper describes the CPS briefly and evaluates its performance skill for the two recent cyclones Viyaru and Phailin, converse in nature (in terms of track and intensity) and formed over the Bay of Bengal in 2013. Detailed lifecycles of the cyclone Viyaru and Phailin are described by Kotal et al. (2014). The data sample used in this study is described in section 2. CPS is described briefly in section 3. Forecast performance of CPS is presented in section 4 and summary and conclusions are given in section 5 .

\section{Data sources}

The observed data for the cyclone Viyaru and Phailin such as track positions, intensity, and other variables have been taken from the database of the cyclone division of the Regional Specialized Meteorological Centre (RSMC), IMD, New Delhi. GPP is derived based on dynamical and thermodynamical parameters from the model output of IMD operational Global Forecast System. The predictors selected for the MME are forecast latitude and longitude positions of cyclone at 12-hr intervals up to 120 hours forecasts from the five NWP models namely, IMD-GFS, IMD-WRF, NCEP-GFS, UKMO, and JMA. Various dynamical and thermodynamical parameters as predictors for SCIP model for predicting cyclone intensity (at 12 hourly intervals up to 72 hours) are derived from the model outputs of IMD operational Global Forecast 
System and these parameters are also used for prediction of rapid intensification. Hurricane-WRF Model (HWRF) model forecasts for cyclone track and intensity are also used for comparison with MME and SCIP.

\section{NWP-based objective cyclone forecast system (CPS)}

During the last two decades, weather forecasting all over the world has greatly benefited from the guidance provided by the NWP models. However, limitations remain, particularly in the prediction of intensity of tropical cyclones (Elsberry et al. 2007; Houze et al. 2007). There is variation of forecasts among NWP models and requirements are also different for different forecast services. Therefore, there is a need to generate more skillful, consensus and requirement-based products. As statistical post-processing can add skill to dynamical forecasts, various post-processed and value added NWP-based special products are prepared for real time cyclone forecasting. The objective of the CPS was:

- To add skill to dynamical forecasts by statistical post-processing.

- To generate consensus forecast from different NWP model forecasts.

- To develop a collective approach to address various components for improving cyclone forecast service.

The five-step NWP based CPS for the operational cyclone forecasting work is described below.

\subsection{Step-I: Genesis potential parameter (GPP)}

The objective was to locate a potential cyclogenesis zone over the sea and to understand the potential for intensification of a system in the early stages of development.

A cyclone genesis parameter, termed as the genesis potential parameter (GPP), for the Indian seas is developed (Kotal et al. 2009). The parameter, which is defined as the product of four variables, namely vorticity at $850 \mathrm{hPa}$, middle tropospheric relative humidity, middle tropospheric instability, and the inverse of vertical wind shear, is computed based on outputs of IMD GFS T574/L64 (analysis as well as forecasts). The parameter is operationally used for distinction between nondeveloping and developing systems in their early development stages. The composite GPP value (area average) is found to be around three to five times greater for developing systems than for non-developing systems and the threshold value of
GPP was found 8.0 or more for developing systems. The analysis and forecasts of the parameter in the early development stage of a cyclonic storm are found to provide a useful predictive signal for intensification of the system.

The grid point analysis and forecast of the genesis parameter up to 7 days is also generated in real time (Kotal and Bhattacharya 2013). Higher value of the GPP over a region indicates higher potential of genesis over the region. The region with GPP value $\geq 30$ is found to be a high potential zone for cyclogenesis. The analysis of the parameter and its effectiveness for cyclone Viyaru and Phailin over the Bay of Bengal in 2013 affirm its usefulness as a predictive signal (4-7 days in advance) for cyclogenesis over the NIO.

\subsection{Step-II: Multi-model ensemble (MME) technique for track prediction}

As there are variations of track forecasts among different NWP models, the objective of this component was to generate a consensus track forecast of NWP models by MME. The MME technique (Kotal and Roy Bhowmik 2011) is based on collective bias correction by multiple linear regression based minimization principle for the model forecast positions with respect to the observed position of cyclones. The predictors selected for the ensemble technique are forecast latitude and longitude positions at 12-hr interval up to 120 hours of five NWP models IMD-GFS, IMD-WRF, NCEP-GFS, UKMO, and JMA. The weights of the models for the MME technique are not static. The weights are generated dynamically before each cyclone by considering the extended dataset comprising of previous cyclones. These modified coefficients are then applied for forecasting the track of the present cyclone in real-time.

\subsection{Step-III: Dynamical-statistical model for cyclone intensity prediction (SCIP)}

The objective of this component was intensity prediction at 12-hr intervals up to 72 hours. A dynamical statistical model (SCIP) (Kotal et al. 2008) has been developed and implemented for real time forecasting of intensity at 12-hr intervals up to 72 hours. The model coefficients are derived based on model analysis of past cyclones. The parameters selected as predictors are: initial storm intensity, intensity changes during past 12 hours, storm motion speed, initial storm latitude position, vertical wind shear averaged along the storm track, vorticity at $850 \mathrm{hPa}$, divergence at $200 \mathrm{hPa}$, and sea surface temperature (SST). 


\subsection{Step-IV: Rapid intensification (RI) index}

The rapid intensification $(\mathrm{RI})$ is defined as an increase of intensity by $30 \mathrm{kt}\left(15.4 \mathrm{~ms}^{-1}\right)$ or more during subsequent 24 hours (Kotal et al. 2012). The objective was probability forecast of rapid intensification. A rapid intensification index (RII) is developed for tropical cyclones over the Bay of Bengal (Kotal and Roy Bhowmik 2013). The RII uses large-scale characteristics of tropical cyclones to estimate the probability of rapid intensification (RI) over the subsequent 24 hours. The RII technique is developed by combining threshold (index) values of the eight variables for which statistically significant differences are found between RI and non-RI cases. The variables are: storm latitude position, previous 12hr intensity change, initial storm intensity, vorticity at $850 \mathrm{hPa}$, divergence at $200 \mathrm{hPa}$, vertical wind shear, lower tropospheric relative humidity, and storm motion speed. The probability of RI is found to increase from $0 \%$ to $100 \%$, when the total number of indices satisfied, increase from zero to eight.

\subsection{Step-V: Decay of intensity after the landfall}

The objective of this final component was to predict decaying intensity after landfall at 6-hr intervals up to 24 hours. Tropical cyclones (TCs) are well known for their destructive potential and impact on human activities. The super cyclone Orissa (1999) illustrated the need for accurate prediction of inland effects of tropical cyclones. The super cyclone of Orissa maintained the intensity of cyclonic storm for about 30 hours after landfall. Because a dense population resides at or near the Indian coasts, the decay forecast has direct relevance to daily activities over a coastal zone (such as transportation, tourism, fishing, etc.) apart from disaster management. In view of this, the decay model (Roy Bhowmik et al. 2005) has been used for real time forecasting of decaying intensity (after landfall) of TCs.

Flow diagram of the five-step objective CPS is shown in figure 1.

\section{Forecast performance of CPS}

\subsection{Forecast skill of GPP for prediction of cyclogenesis}

Grid point forecast of GPP for cyclone Viyaru and Phailin are shown in figures $2(\mathrm{a}-\mathrm{b})$ and $3(\mathrm{a}-\mathrm{b})$, respectively. Figure 2(a) shows that 96-hr forecast based on 7 May 2013 and 72-hr forecast (figure 2b) based on 8 May 2013 valid for 00 UTC 11 May 2013 indicated the potential cyclogenesis zone, where deep depression (initial stage of Viyaru) formed on that date (11 May 2013). Figure 3(a) shows that 168-hr forecast based on 1 October 2013 and 120-hr forecast (figure 3b) based on 3 October 2013 valid for 00 UTC 8 October 2013 indicated the potential cyclogenesis zone, where depression (initial stage of Phailin) formed on that date (8 October 2013). The GPP forecasts for the cyclone Viyaru and Phailin show that the parameter was able to indicate the potential cyclogenesis zone over the Bay of Bengal for both the cyclones 4-7 days in advance.

Analysis and forecasts of area average GPP for cyclone Viyaru and Phailin are shown in figures $4(\mathrm{a}-\mathrm{b})$ and $5(\mathrm{a}-\mathrm{c})$, respectively. The figures show that GPP $\geq 8.0$ (threshold value for intensification into cyclone) for both the systems, clearly indicate their potential to intensify into a cyclonic storm in the early stages of development (T.No. $1.0,1.5,2.0)$.

\subsection{Performance of MME for track prediction}

MME track forecast errors for Viyaru: Eight MME forecast tracks based on initial conditions from 1200 UTC of 10 May 2013 to 0000 UTC of 16 May 2013 (as shown in different colours) along with the observed track of cyclone Viyaru is depicted in figure 6 . The figure shows that from day $1(00$ UTC 10 May 2013) when the system was over the southeast Bay of Bengal, MME correctly predicted the recurvature and landfall at southeast coast of Bangladesh near Chittagong. The consensus forecast MME outperformed all the forecasts up to 72 hours, and it ranged from $79 \mathrm{~km}$ at $12 \mathrm{hr}$ to $169 \mathrm{~km}$ at $72 \mathrm{hr}$. ECMWF model forecast was superior to other model forecasts for 84-108 hr forecast (104$255 \mathrm{~km}$ ) and again MME forecast error $(176 \mathrm{~km})$ is lowest at $120 \mathrm{hr}$ (figure 7 ). The number of forecast cases for each lead time is shown in table 1 . Figure 8 shows that landfall point forecast error of NWP models was ranged from 54 to $183 \mathrm{~km}$. The figure also shows that the mean landfall forecast error of MME was the lowest (54 km) and NCEP GFS forecast error was the highest $(183 \mathrm{~km})$.

MME track forecast errors for Phailin: All the NWP model tracks and MME forecast tracks based on different initial conditions from 0000 UTC of 8 October 2013 to 0000 UTC of 10 October 2013 along with the observed track of cyclone Phailin is depicted in figure 9. The figure shows that there was wide variation of forecast tracks of NWP models (figure 9a, c, e), but from day 1 (0000 UTC 8 October to 0000 UTC 10 October 2013), MME predicted (figure 9b, d, f) correctly and consistently the landfall point at Gopalpur (Odisha). The mean track error of MME was about $65 \mathrm{~km}$ at $12 \mathrm{hr}$ 


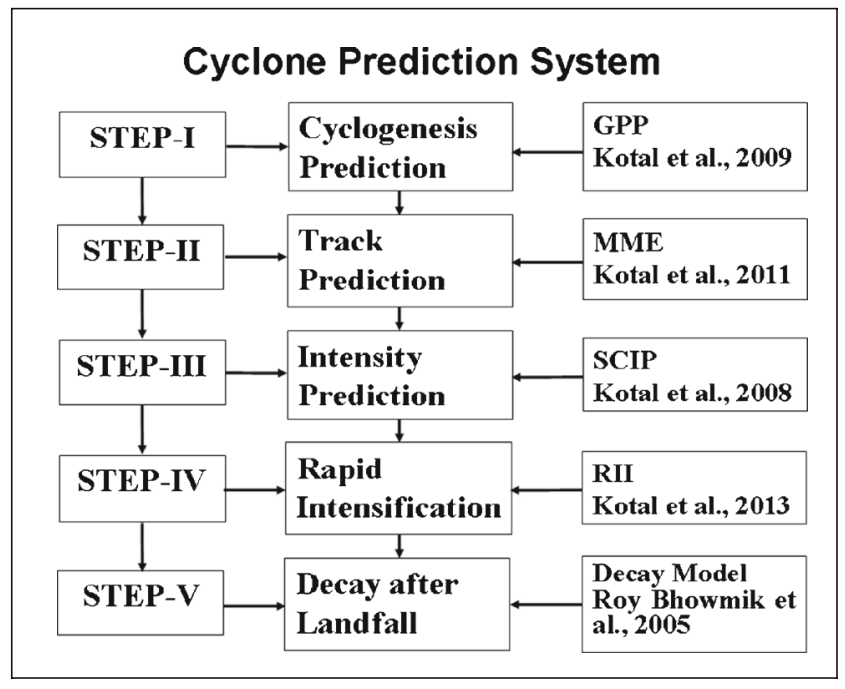

Figure 1. Flow diagram of cyclone prediction system (CPS).

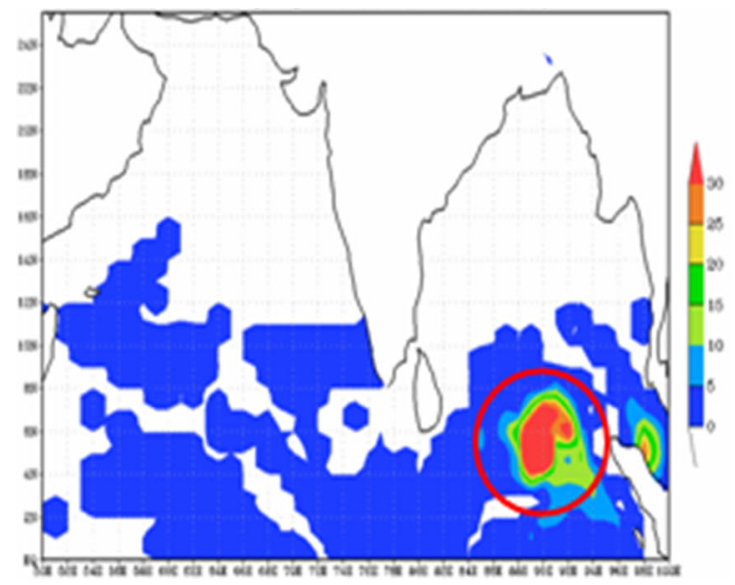

(a) to $150 \mathrm{~km}$ at $120 \mathrm{hr}$ (figure 10). The number of forecast cases for each lead time during the lifecycle of cyclone Phailin is shown in table 2. Landfall point forecast errors of all NWP models at different forecast lead times (figure 11) show that some models predicted north of actual landfall point and some predicted south of actual landfall point with a maximum limit up to about $340 \mathrm{~km}$ towards north and up to $215 \mathrm{~km}$ towards south. Under this wide extent of landfall point forecasts of NWP models, MME was able to predict near actual landfall point (Gopalpur) consistently (figure 9b, d, f) with an average error of $20 \mathrm{~km}$, the lowest among all NWP models (figure 12). Landfall point forecast error of MME ranged from 39 to $0 \mathrm{~km}$ before 113 to $5 \mathrm{hr}$ of landfall time (figure 11). Landfall time forecast errors of NWP models at different forecast lead times (figure 13) show that some models predicted earlier than actual landfall time and

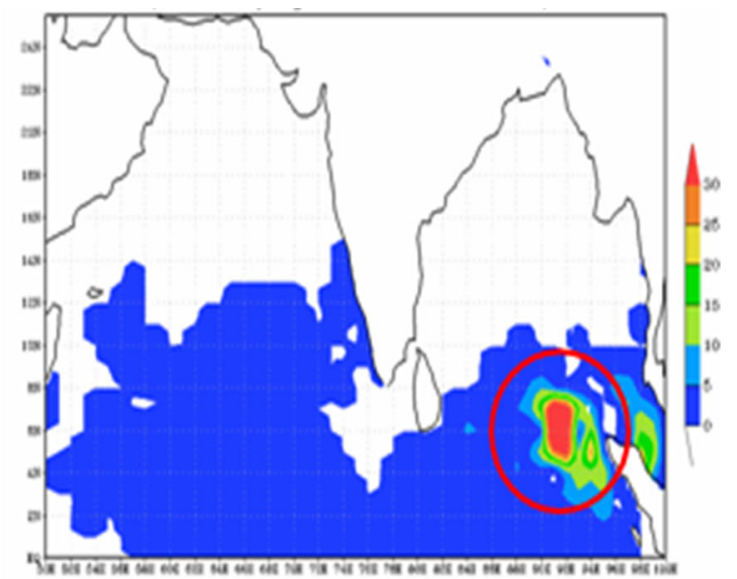

(b)

Figure 2. Grid point forecasts of GPP for cyclone Viyaru (genesis forecast zone marked by circle). (a) 96-hr forecast and (b) 72-hr forecast.

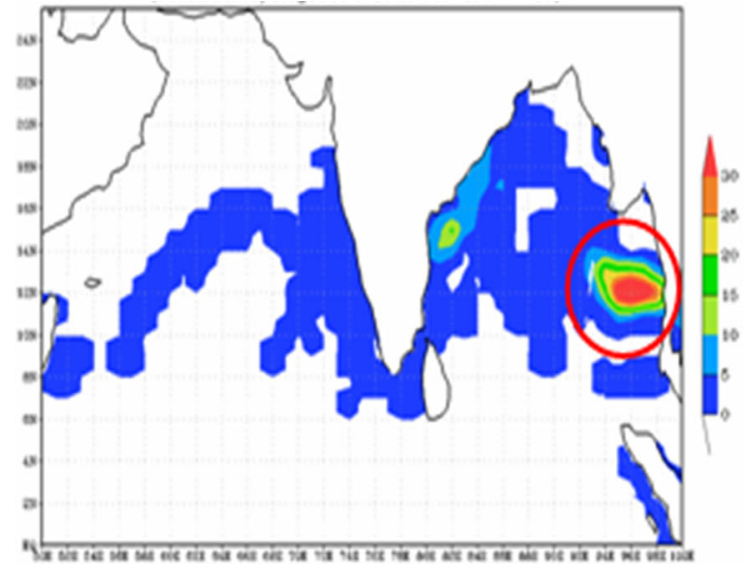

(a)

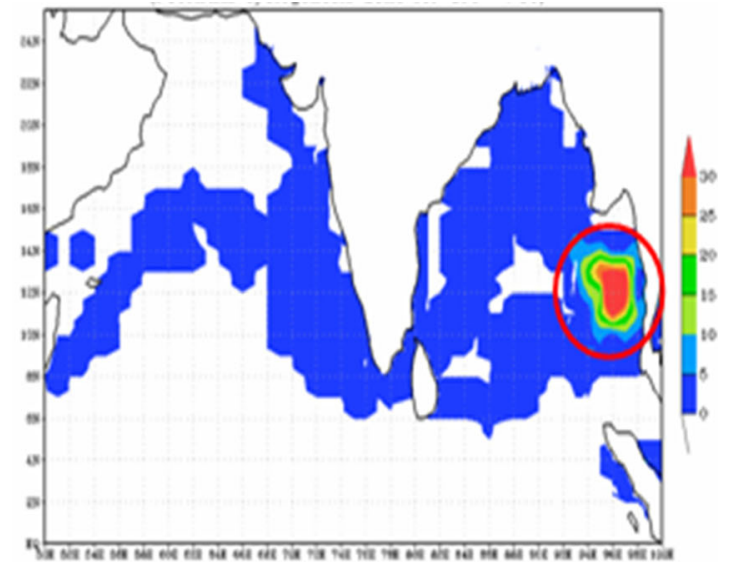

(b)

Figure 3. Grid point forecasts of GPP for cyclone Phailin (genesis forecast zone marked by circle). (a) 168-hr forecast and (b) 120 -hr forecast. 

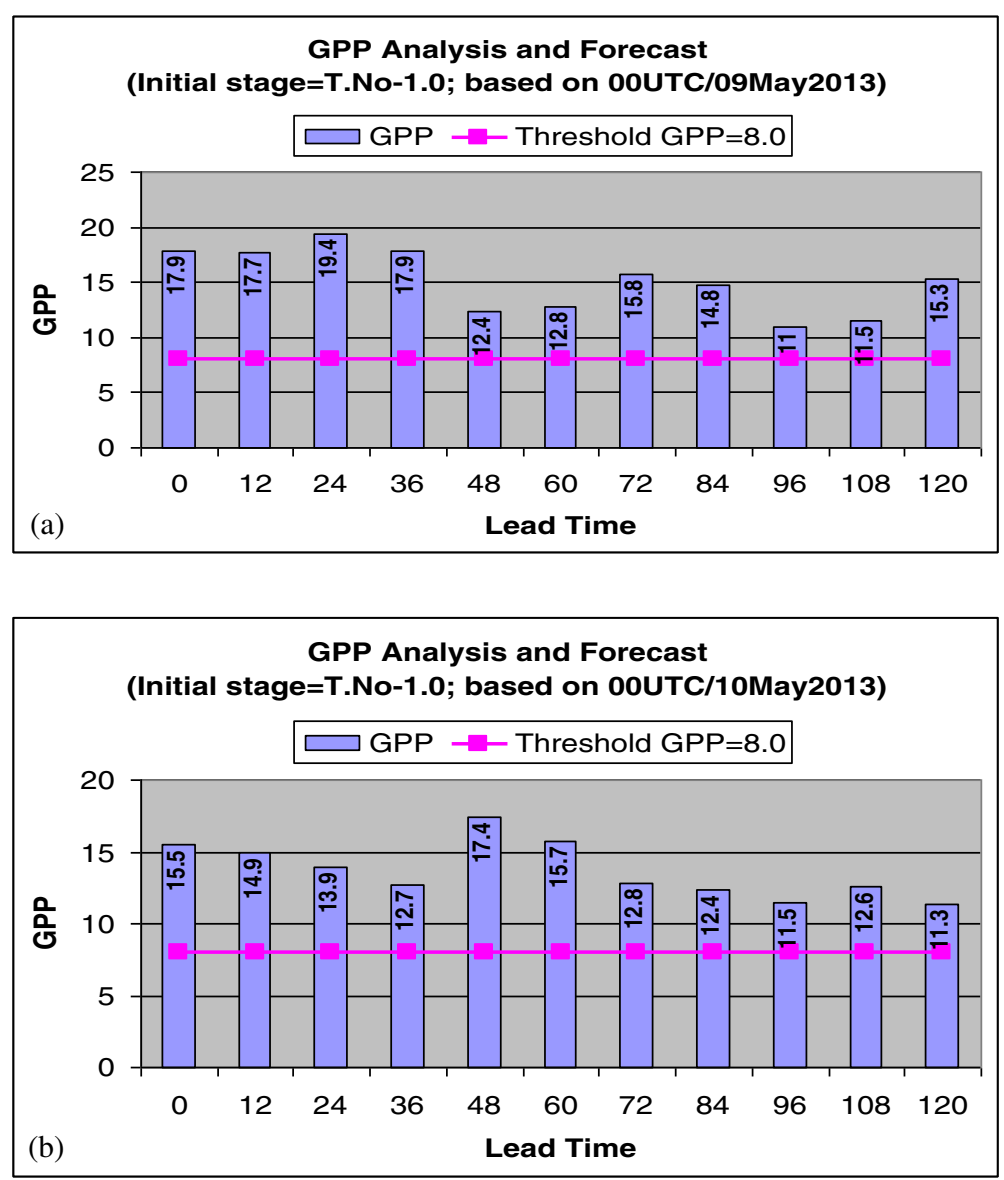

Figure 4. Analysis and forecasts of area average GPP for cyclone Viyaru. GPP forecast based on (a) 00 UTC 9 May 2013 at stage T.No. 1.0 and (b) 00 UTC 10 May 2013 at stage T.No. 1.0.

some predicted later than actual landfall time with a maximum limit up to $21 \mathrm{hr}$ delay and up to $6 \mathrm{hr}$ earlier than actual landfall time. Under this wide extent of landfall time forecasts, MME landfall time error was consistently low. Average land fall time error (figure 14) shows that MME landfall time forecast error was the least $(1.9 \mathrm{hr})$ compared to other models.

\subsection{Performance of SCIP for intensity prediction}

Intensity forecast errors for Viyaru: Average absolute error (AAE) and root mean square error (RMSE) of SCIP and HWRF intensity forecast error for cyclone Viyaru is presented in figure 15(a and b) respectively. Intensity forecasts by SCIP and HWRF show that statistical-dynamical model forecast (SCIP) was superior to HWRF forecasts for cyclone Viyaru (figure 15a) and was able to predict nonintensification of the system. The AAE for SCIP ranged from $1 \mathrm{kt}$ at $12 \mathrm{hr}$ to $10 \mathrm{kt}$ at 72 hr with highest error $11 \mathrm{kt}$ at $60 \mathrm{hr}$. The AAE for HWRF ranged from $27 \mathrm{kt}$ at $12 \mathrm{hr}$ to $23 \mathrm{kt}$ at 72 hr with lowest error $9 \mathrm{kt}$ at $36 \mathrm{hr}$. The RMSE for SCIP ranged from $2 \mathrm{kt}$ at $12 \mathrm{hr}$ to $12 \mathrm{kt}$ at $72 \mathrm{hr}$, whereas RMSE for HWRF was ranged from $30 \mathrm{kt}$ at $12 \mathrm{hr}$ to $28 \mathrm{kt}$ at $72 \mathrm{hr}$.

Intensity forecast errors for Phailin: For the cyclone Phailin, intensity prediction (at stages of 12-hr intervals) by SCIP is shown in figure 16. The figure shows that SCIP model was able to predict the very severe stage $(65 \mathrm{kt})$ of the Phailin at all stages of forecast from 00 UTC of 8 October to 00 UTC of 12 October 2013 and for subsequent forecasts it predicted more than $65 \mathrm{kt}$. Although the forecast based on 00 UTC of 8 October 2013 underestimated the intensity, it predicted maximum wind speed $65 \mathrm{kt}$ (very severe cyclonic storm). Also the model could not predict the nonintensification phase of the Phailin from 0300 UTC of 11 October to 1200 UTC of 12 October 2013 during which the cyclone maintained constant intensity of 115 kt. Average absolute error (AEE) and root mean square error (RMSE) of SCIP and HWRF forecast error is presented in figure 17 ( $\mathrm{a}$ and $\mathrm{b}$ ) respectively. Intensity forecasts by SCIP and HWRF show that statistical-dynamical model forecast (SCIP) was superior to HWRF up to 48 hours, HWRF was better at $60-\mathrm{hr}$ and 72 -hr forecasts. AAE of SCIP was $31 \mathrm{kt}$ at $60-\mathrm{hr}$ and $37 \mathrm{kt}$ at 72 -hr. AEE of 

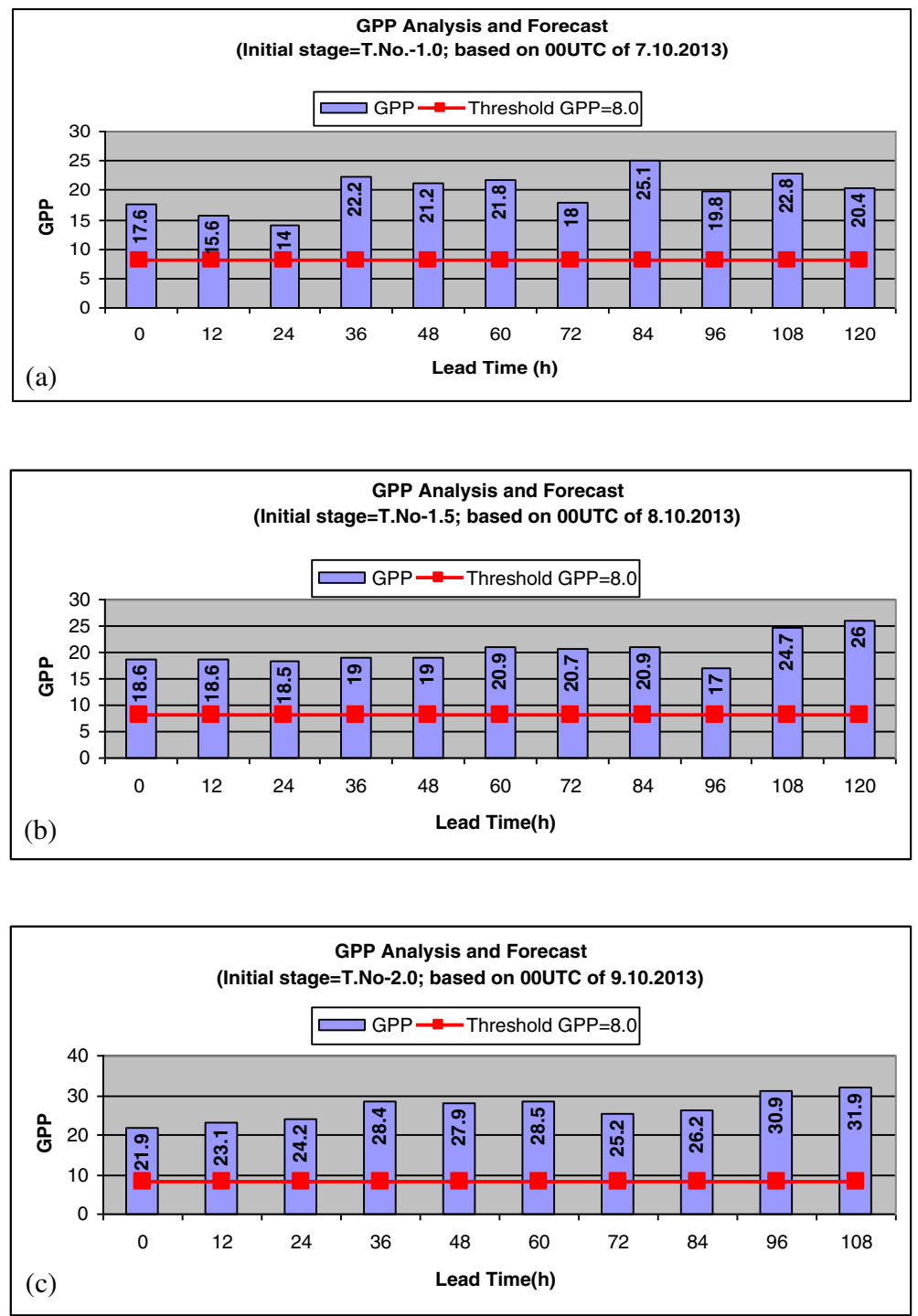

Figure 5. Analysis and forecasts of area average GPP for cyclone Phailin. GPP forecast based on (a) 00 UTC 7 October 2013 at stage T.No. 1.0, (b) 00 UTC 8 October 2013 at stage T.No. 1.5, and (c) 00 UTC 9 October 2013 at stage T.No. 2.0.

HWRF was $28 \mathrm{kt}$ and $19 \mathrm{kt}$ at 60 and $72 \mathrm{hr}$, respectively. The RMSE for SCIP ranged from $14 \mathrm{kt}$ at $12 \mathrm{hr}$ to $37 \mathrm{kt}$ at $72 \mathrm{hr}$, whereas RMSE for HWRF was ranged from $19 \mathrm{kt}$ at $12 \mathrm{hr}$ to $20 \mathrm{kt}$ at $72 \mathrm{hr}$ with highest error $32 \mathrm{kt}$ at $36 \mathrm{hr}$. The landfall intensity of Phailin was $115 \mathrm{kt}$. Landfall intensity predicted by SCIP model (figure 18) shows that, from 3 days before landfall time (from initial cyclonic storm stage at 1200 UTC of 09 October 2013), the model predicted the landfall intensity of very severe cyclonic storm with reasonable accuracy.

\subsection{Forecast skill of RI index for prediction of rapid intensification}

Rapid intensification (RI) is defined as the increase of intensity by $30 \mathrm{kt}$ or more during subsequent 24 hours. Six forecasts for probability of rapid intensification of cyclone Viyaru were issued. Among the six forecasts (table 3), five forecasts were 'very low' (probability 2.6\%-9.4\%) and one forecast was 'low' (probability 22\%). For cyclone Viyaru, no rapid intensification phase occurred and RI index was able to predict nonoccurrence of rapid intensification of cyclone Viyaru during its lifetime.

The probability forecasts of RI for cyclone Phailin is given in table 4 . The table shows that the $\mathrm{RI}$ index was able to predict occurrence as well as nonoccurrence of RI of cyclone Phailin during its lifetime except forecast for 12 UTC of 09 October 2013 and 00 UTC of 11 October 2013.

\subsection{Performance of Decay model for intensity prediction after landfall}

Decay (after landfall) prediction curve (6-hourly) for cyclone Viyaru (figure 19) shows slight slow 
decay compared to observed decay. The absolute error was 8 and $7 \mathrm{kt}$ at 6 and $12 \mathrm{hr}$, respectively. For the cyclone Phailin, decay (after landfall) prediction curve (figure 20a-b) shows slightly faster decay compared to observed decay. The average absolute error was $13 \mathrm{kt}$ at $6 \mathrm{~h}, 5 \mathrm{kt}$ at $12 \mathrm{hr}$ and $18 \mathrm{hr}$ and $3 \mathrm{kt}$ at $24 \mathrm{hr}$.

The decay forecast errors for cyclone Viyaru and Phailin show that the decay model correctly predicted the decaying nature after landfall for both the cyclones.

\section{Summary and conclusions}

This study evaluates the performance of forecasts in terms of a numerical measure of forecast errors of a five-step dynamical-statistical objective cyclone

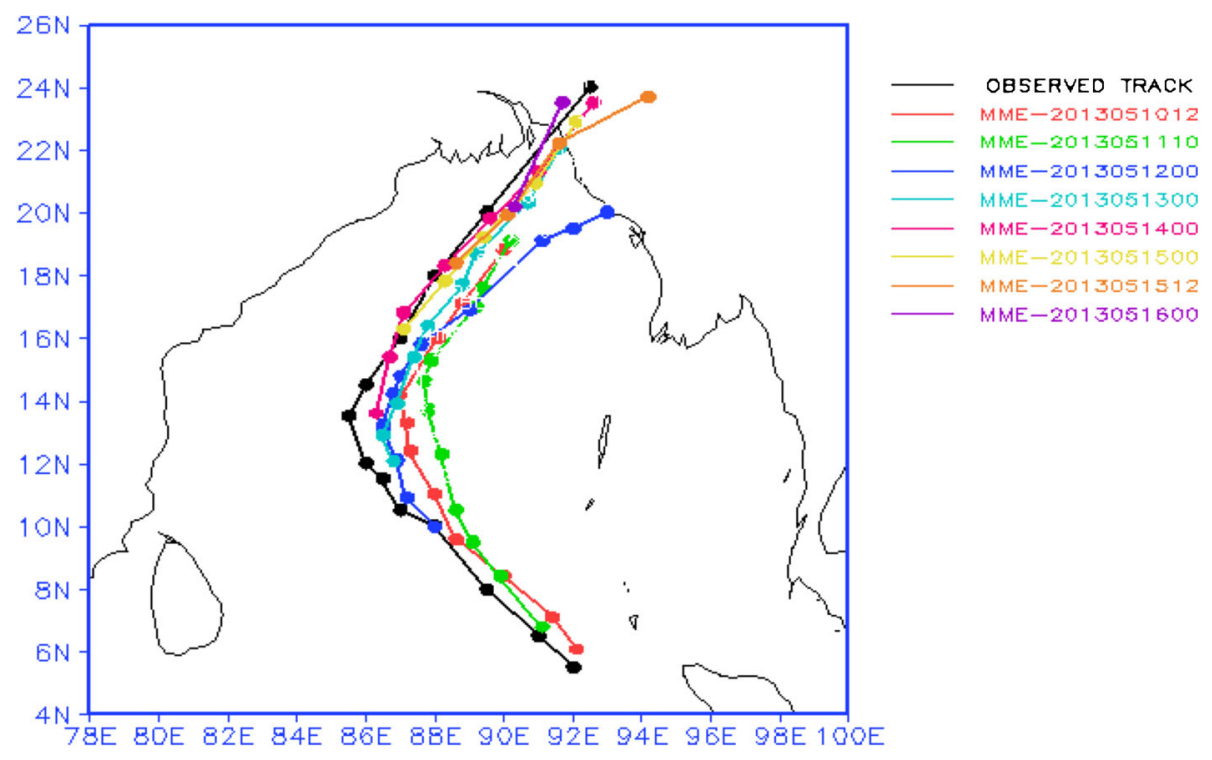

Figure 6. MME forecast tracks based on different initial conditions for cyclone Viyaru.

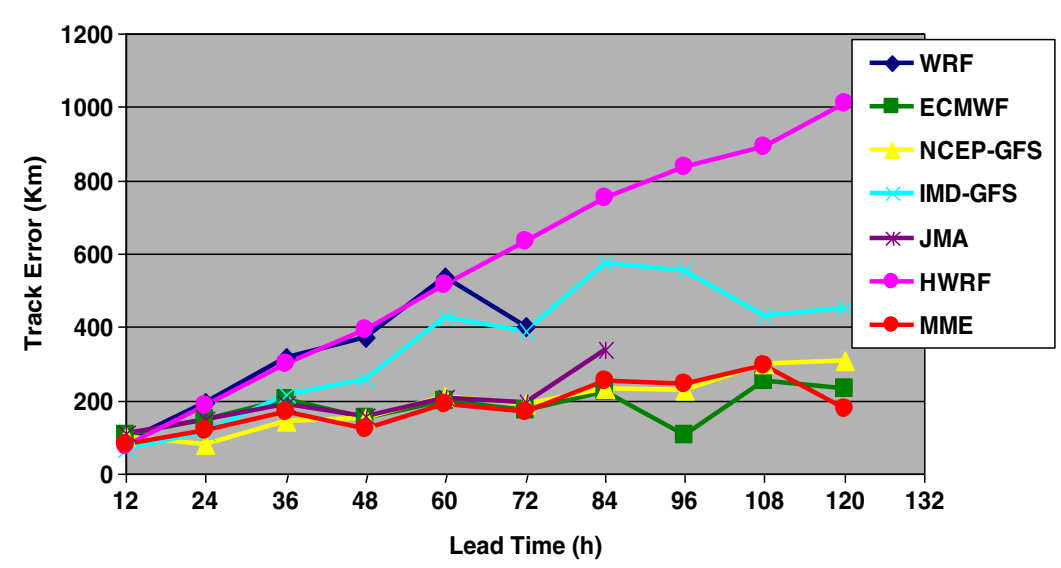

Figure 7. Mean track forecast errors $(\mathrm{km})$ of NWP models for cyclone Viyaru.

Table 1. Number of forecasts verified for cyclone Viyaru at different lead time.

\begin{tabular}{lcccccccccc}
\hline Lead time $\rightarrow$ & $12 \mathrm{hr}$ & $24 \mathrm{hr}$ & $36 \mathrm{hr}$ & $48 \mathrm{hr}$ & $60 \mathrm{hr}$ & $72 \mathrm{hr}$ & $84 \mathrm{hr}$ & $96 \mathrm{hr}$ & $108 \mathrm{hr}$ & $120 \mathrm{hr}$ \\
\hline IMD-GFS & 7 & 7 & 6 & 4 & 4 & 3 & 3 & 2 & 1 & 1 \\
WRF & 8 & 7 & 6 & 5 & 5 & 4 & - & - & - & - \\
JMA & 8 & 7 & 6 & 5 & 5 & 4 & 4 & - & - & - \\
NCEP & 8 & 7 & 6 & 5 & 5 & 4 & 4 & 3 & 2 & 2 \\
ECMWF & 8 & 7 & 6 & 5 & 5 & 4 & 4 & 3 & 3 & 2 \\
MME & 8 & 7 & 6 & 5 & 5 & 4 & 4 & 3 & 3 & 2 \\
HWRF & 10 & 9 & 8 & 7 & 6 & 5 & 4 & 3 & 2 & 1 \\
\hline
\end{tabular}




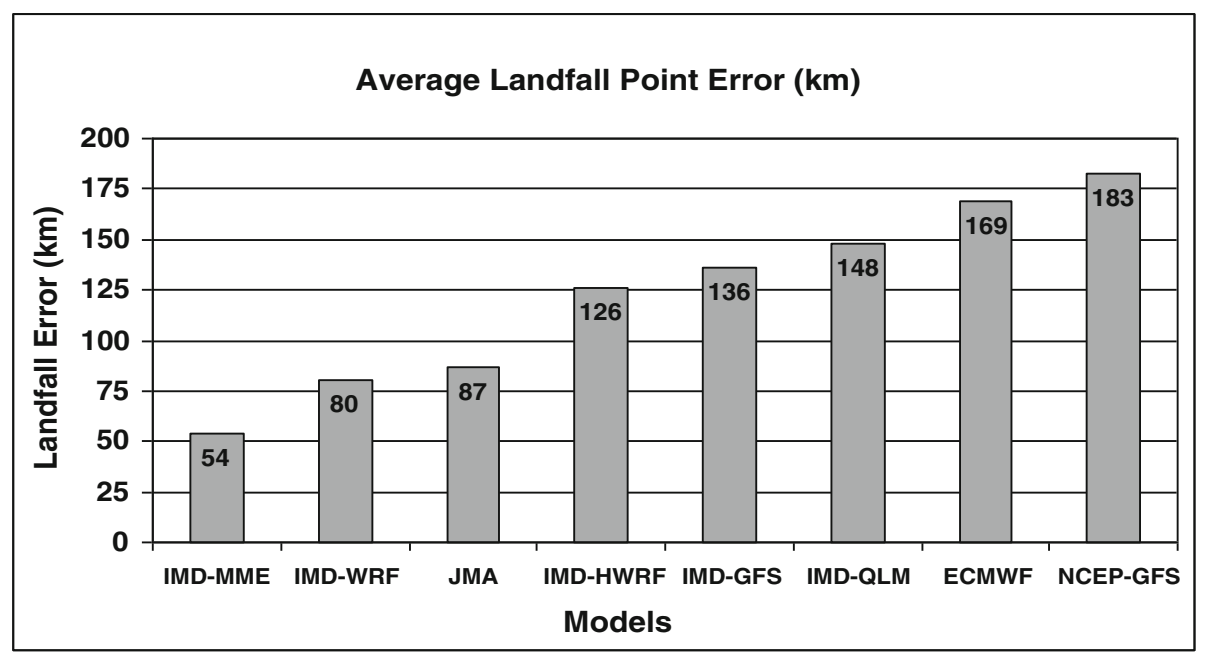

Figure 8. Average landfall point forecast errors $(\mathrm{km})$ of NWP models for cyclone Viyaru.

prediction system (CPS) used for real time forecasting of the two recent cyclones Viyaru and Phailin (converse in nature in terms of track and intensity) formed over the Bay of Bengal in 2013. The five steps consist of prediction of (i) cyclogenesis, (ii) track, (iii) intensity, (iv) probability of rapid intensification, and (v) decaying intensity after the landfall. The performances of each component of the CPS are summarized below.

(i) The grid point analysis and forecasts of genesis potential parameter (GPP) show that the GPP was able to predict the formation and location of the two systems 4-7 days before its formation. Analysis and forecasts of area average GPP indicated their potential to intensify into cyclones at very early stages (T. No. 1.0, 1.5, 2.0) of their development.

(ii) The multimodel ensemble (MME) track forecast correctly predicted the recurvature and landfall at southeast coast of Bangladesh near Chittagong of the cyclone Viyaru. The MME outperformed all other member model track forecasts up to $72 \mathrm{hr}$, and forecast error ranged from $79 \mathrm{~km}$ at $12 \mathrm{hr}$ to $169 \mathrm{~km}$ at $72 \mathrm{hr}$. Landfall point forecast error of MME was least, 63 to $25 \mathrm{~km}$ before 56 to $8 \mathrm{hr}$ of landfall time.

The MME was able to predict correctly and consistently the landfall of cyclone Phailin at Gopalpur (Odisha) from day 1 (113 hr before its landfall). The average landfall point error was $20 \mathrm{~km}$, the lowest among all NWP models.

(iii) Intensity forecast by statistical-dynamical model (SCIP) was superior to HWRF forecasts up to $72 \mathrm{hr}$ for cyclone Viyaru and was able to capture nonintensification of the system. The average absolute error (AAE) for SCIP ranged from $1 \mathrm{kt}$ at $12 \mathrm{hr}$ to $10 \mathrm{kt}$ at $72 \mathrm{hr}$ and for HWRF it ranged from $27 \mathrm{kt}$ at $12 \mathrm{hr}$ to $23 \mathrm{kt}$ at $72 \mathrm{hr}$.

The SCIP model was able to predict the very severe stage of the Phailin at all stages of forecast. The SCIP was superior to HWRF up to $48 \mathrm{hr}$, but HWRF forecast error was less at 60 and $72 \mathrm{hr}$ forecasts. AAE of SCIP ranged from $10 \mathrm{kt}$ at $12 \mathrm{hr}$ to $25 \mathrm{kt}$ at $48 \mathrm{hr}$ and it was $31 \mathrm{kt}$ at $60 \mathrm{hr}$ and 37 kt at $72 \mathrm{hr}$. AEE of HWRF was ranged from $17 \mathrm{kt}$ at $12 \mathrm{hr}$ to $31 \mathrm{kt}$ at $48 \mathrm{hr}$ and it was 28 and $19 \mathrm{kt}$ at 60 and $72 \mathrm{hr}$, respectively. The SCIP model was able to predict landfall intensity of cyclone Phailin with reasonable accuracy.

(iv) Rapid intensification (RI) is defined as the increase of intensity by $30 \mathrm{kt}$ or more during subsequent 24 hours. For cyclone Viyaru, no rapid intensification phase occurred and RI index was able to predict nonoccurrence phases of cyclone Viyaru during its lifetime. RI index was able to predict occurrence phase as well as nonoccurrence phases of RI of cyclone Phailin during its lifetime.

(v) Decay (after landfall) prediction at 6-hourly interval for cyclone Viyaru was slightly slow compared to observed decay. The absolute error was 8 and $7 \mathrm{kt}$ at 6 and $12 \mathrm{hr}$, respectively. For the cyclone Phailin, forecast decay was slightly fast compared to observed decay. The average absolute error was $13 \mathrm{kt}$ at $6 \mathrm{hr}$, $5 \mathrm{kt}$ at $12 \mathrm{hr}$ and $18 \mathrm{hr}$, and $3 \mathrm{kt}$ at $24 \mathrm{hr}$. The decay forecast errors for cyclone Viyaru and Phailin show that the decay model correctly predicted the decaying nature after landfall for both the cyclones. 

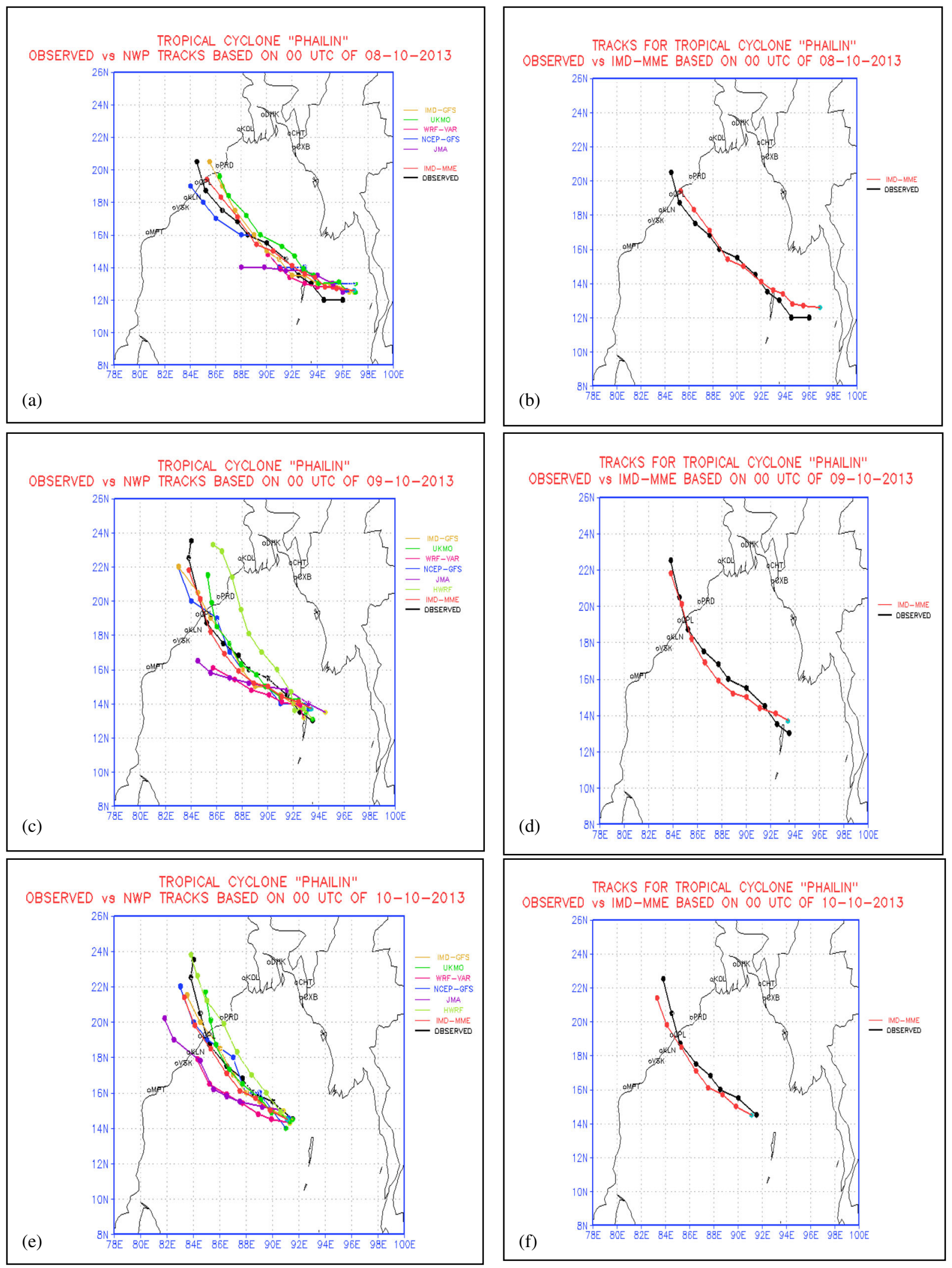

Figure 9. MME forecast tracks based on different initial conditions for cyclone Phalin. (a) All model forecast tracks based on 00 UTC 8 October 2013, (b) observed track (black) and MME forecast track (red) based on 00 UTC 8 October 2013, (c) all model forecast tracks based on 00 UTC 9 October 2013, (d) observed track (black) and MME forecast track (red) based on 00 UTC 9 October 2013, (e) all model forecast tracks based on 00 UTC 10 October 2013, and (f) observed track (black) and MME forecast track (red) based on 00 UTC 10 October 2013. 
All the components of cyclone forecasts (cyclogenesis, track, intensity, rapid intensification, decay after landfall) by objective cyclone prediction system (CPS) generated in real time show that statistical post-processing added skill to dynamical forecasts and provided very useful guidance on landfall point, landfall time, intensity, rapid intensification phases, and decay after landfall to operational forecasters. The results also demonstrate the potential of the CPS for operational cyclone forecasting services. However, we also wish to emphasize that the technique described in the paper is not a complete solution to a cyclone forecaster's problems. For example, the result shows

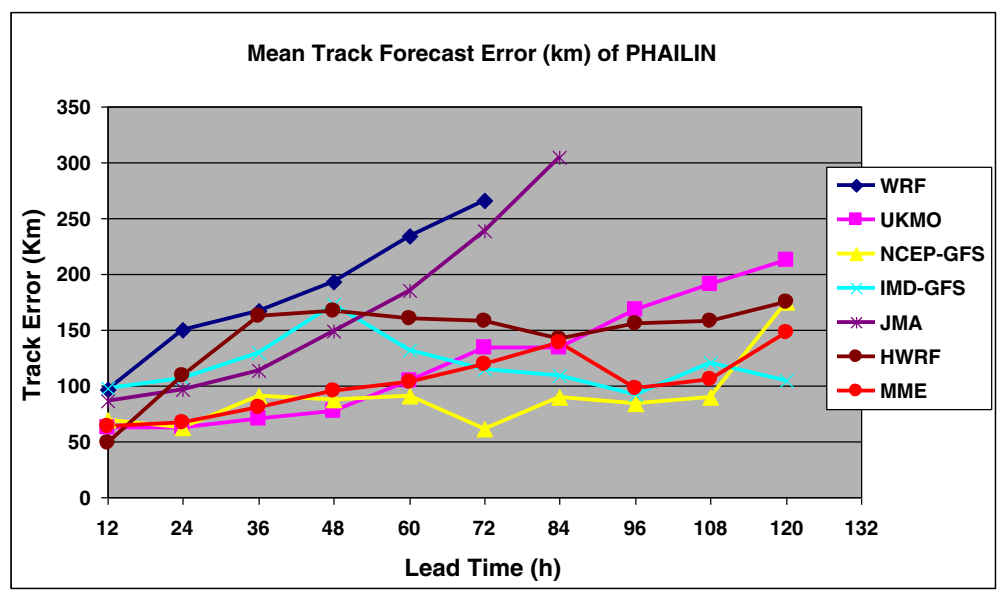

Figure 10. Mean track forecast errors $(\mathrm{km})$ of NWP models for cyclone Phalin.

Table 2. Number of forecasts verified for cyclone Phailin at different lead time.

\begin{tabular}{lcccccccccc}
\hline Lead time $\rightarrow$ & $12 \mathrm{hr}$ & $24 \mathrm{hr}$ & $36 \mathrm{hr}$ & $48 \mathrm{hr}$ & $60 \mathrm{hr}$ & $72 \mathrm{hr}$ & $84 \mathrm{hr}$ & $96 \mathrm{hr}$ & $108 \mathrm{hr}$ & $120 \mathrm{hr}$ \\
\hline IMD-GFS & 9 & 9 & 9 & 8 & 6 & 5 & 4 & 3 & 2 & 1 \\
WRF & 9 & 9 & 9 & 8 & 6 & 5 & - & - & - & - \\
JMA & 9 & 9 & 9 & 8 & 6 & 5 & 4 & - & - & - \\
NCEP & 9 & 9 & 9 & 8 & 6 & 5 & 4 & 3 & 2 & 1 \\
UKMO & 9 & 9 & 9 & 8 & 6 & 5 & 4 & 3 & 2 & 1 \\
MME & 9 & 9 & 9 & 8 & 6 & 5 & 4 & 3 & 2 & 1 \\
HWRF & 8 & 8 & 8 & 7 & 6 & 5 & 4 & 3 & 2 & 1 \\
\hline
\end{tabular}

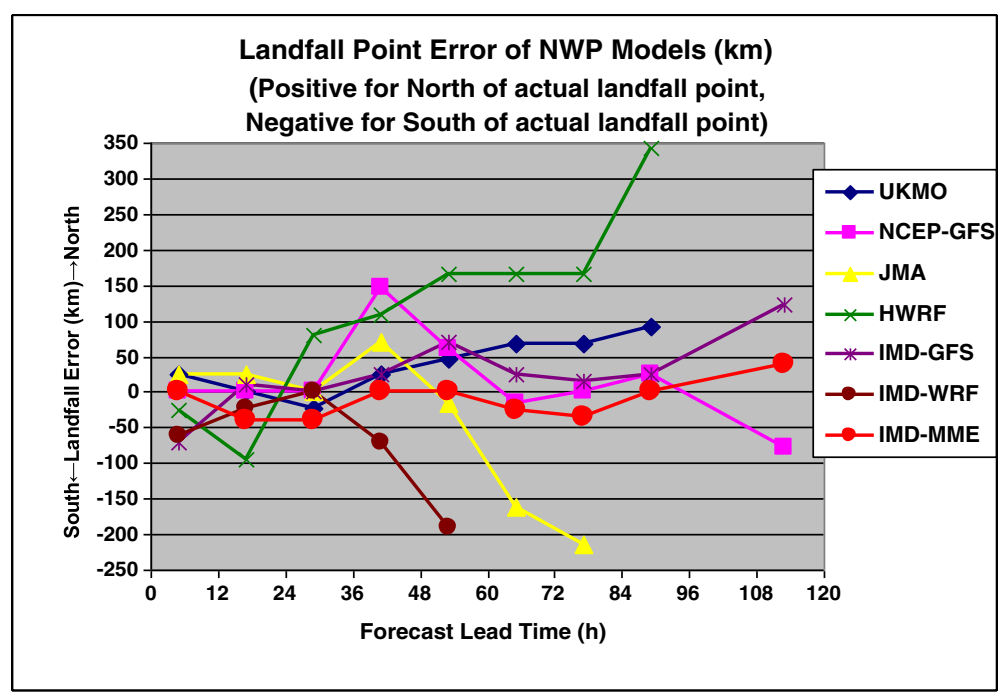

Figure 11. Landfall point forecast errors $(\mathrm{km})$ of NWP models for cyclone Phalin. 


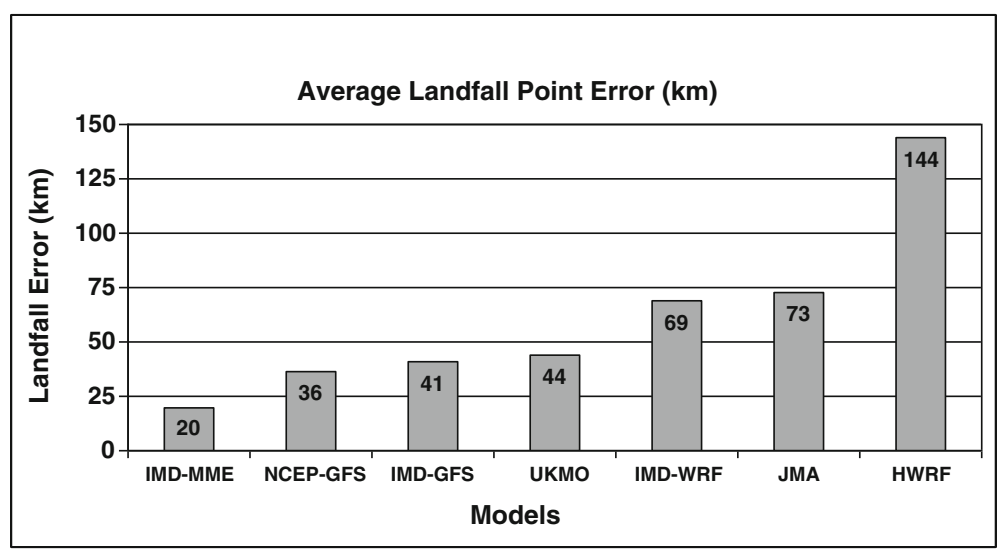

Figure 12. Average landfall point forecast errors $(\mathrm{km})$ of NWP models for cyclone Phalin.

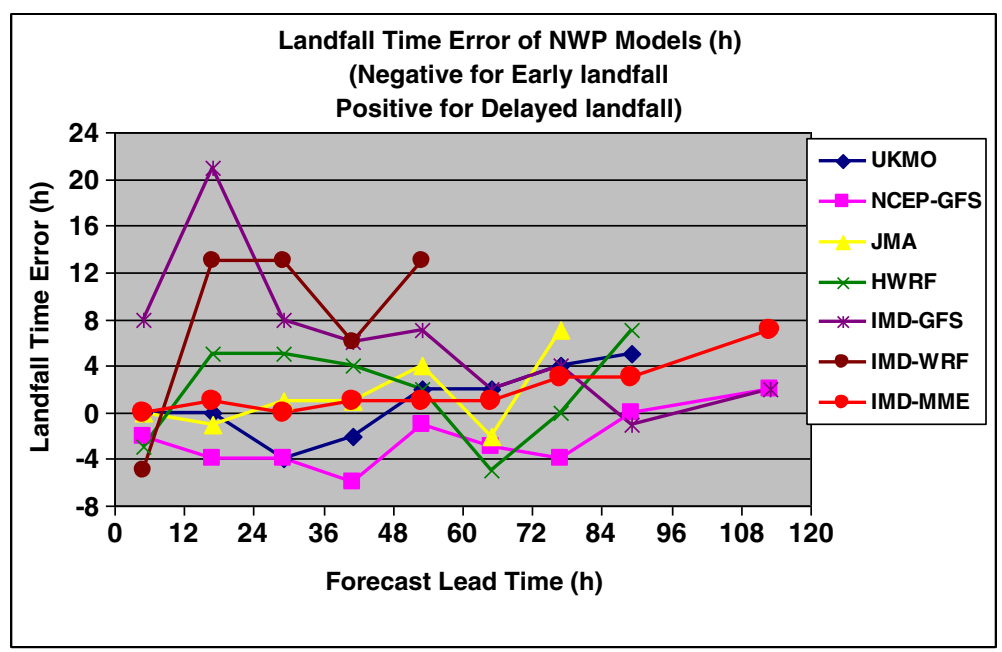

Figure 13. Landfall time forecast errors (h) of NWP models for cyclone Phalin.

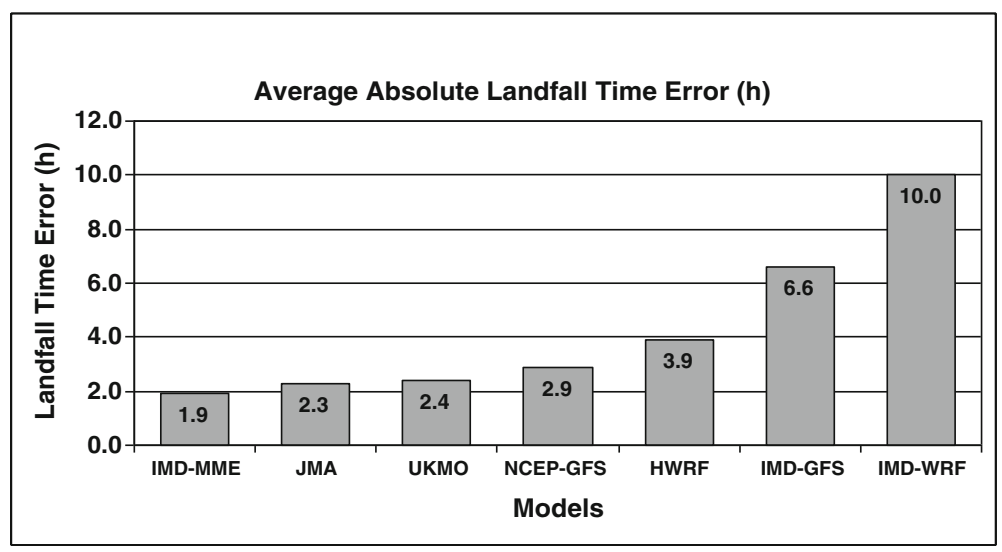

Figure 14. Average landfall time forecast errors (h) of NWP models for cyclone Phalin.

that the SCIP model was able to predict the slow intensification of cyclone Viyaru but was unable to predict the nonintensification phase as well as the rapid intensification phase of cyclone Phailin.
This further affirms that, while the forecasting of tropical cyclone intensity has been quite difficult, the forecasting of significant changes of intensity (rapid intensification, nonintensification) has been 

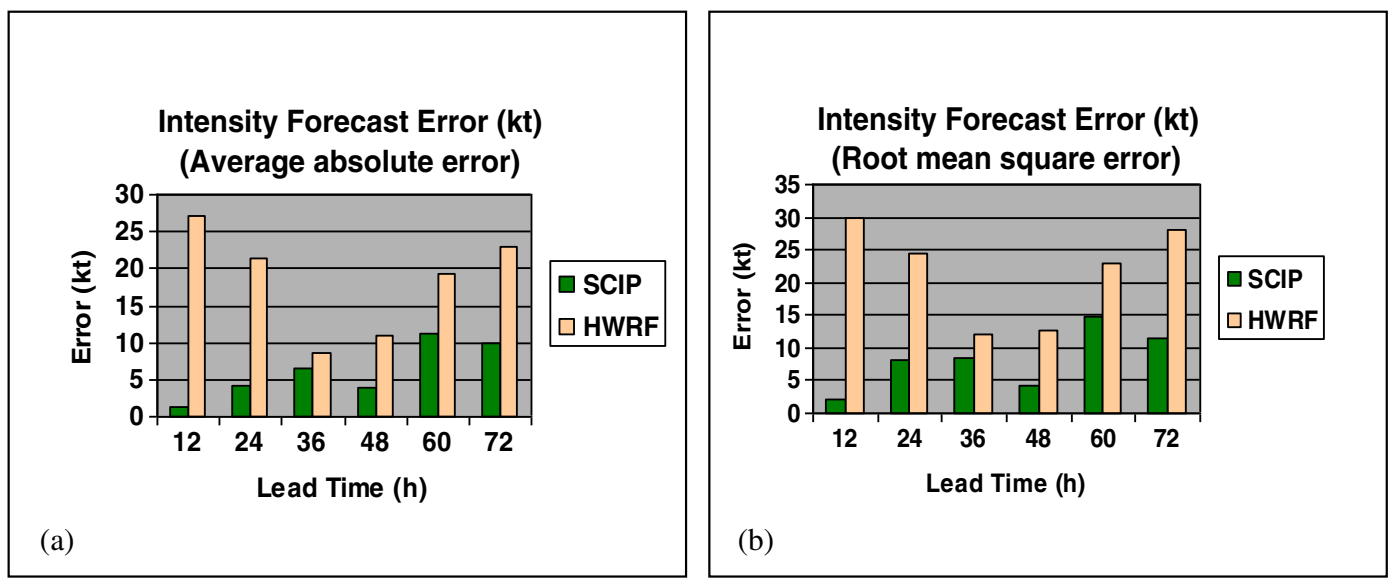

Figure 15. Intensity forecasts error (kt) of SCIP and HWRF model for cyclone Viyaru, (a) average absolute error (AAE) and (b) root mean square error (RMSE).

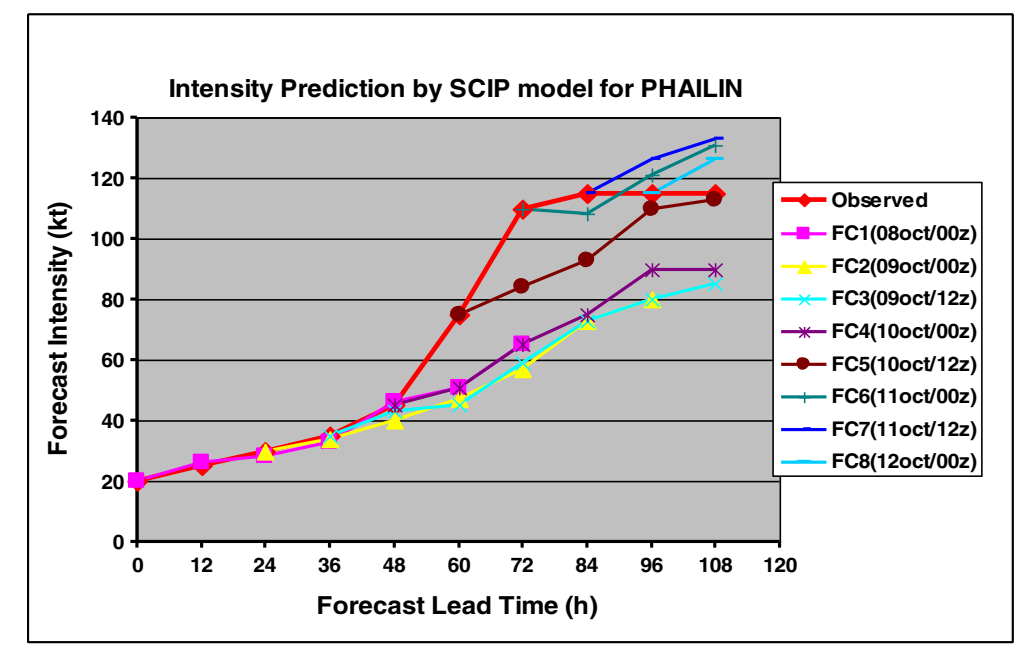

Figure 16. Intensity forecasts by SCIP model for cyclone Phalin.
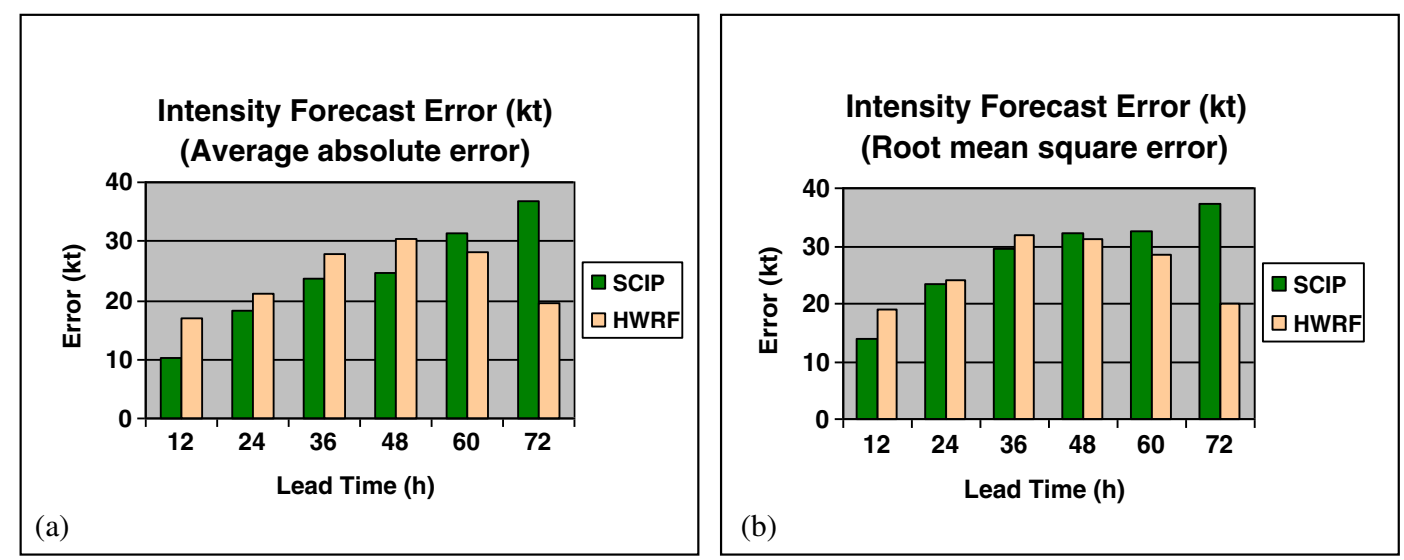

Figure 17. Intensity forecasts error (kt) of SCIP and HWRF model for cyclone Phalin, (a) average absolute error (AAE) and (b) root mean square error (RMSE).

more challenging. In this case, the RI index component of the CPS was able to compensate for the weakness of the SCIP model for prediction of rapid intensification phase of cyclone Phailin but prediction of nonintensification phase of cyclones is a challenge. Although MME technique was able to 


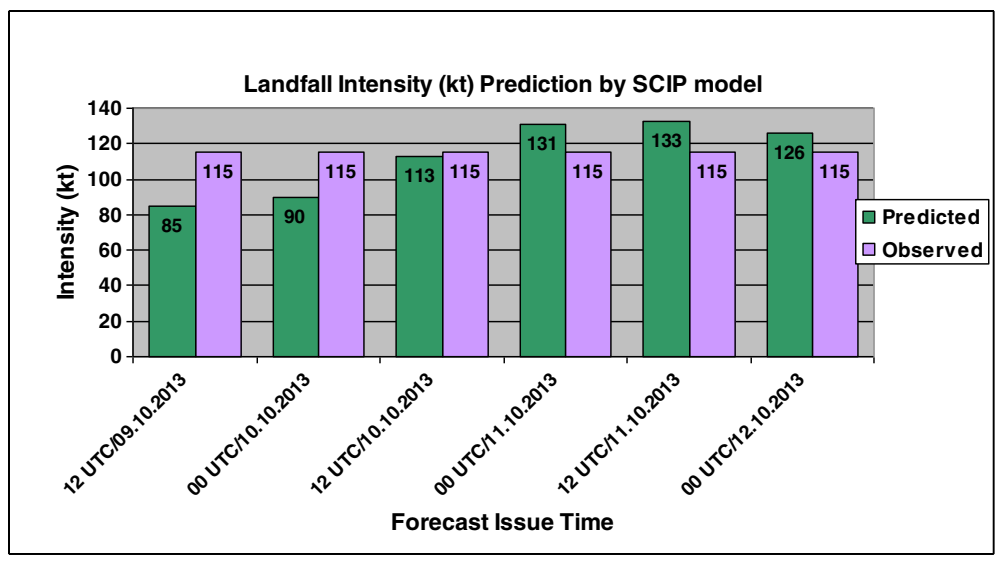

Figure 18. Landfall intensity forecasts by SCIP model for cyclone Phalin.

Table 3. Probability of rapid intensification (RI) for cyclone Viyaru.

\begin{tabular}{lccc}
\hline Forecast based on & $\begin{array}{c}\text { Probability } \\
\text { of RI predicted }\end{array}$ & $\begin{array}{c}\text { Chances of } \\
\text { occurrence predicted }\end{array}$ & Occurrence \\
\hline 00 UTC/11.05.2013 & $9.4 \%$ & Very low & No \\
00 UTC/12.05.2013 & $5.2 \%$ & Very low & No \\
00 UTC/13.05.2013 & $2.6 \%$ & Very low & No \\
00 UTC/14.05.2013 & $5.2 \%$ & Very low & No \\
00 UTC/15.05.2013 & $9.4 \%$ & Very low & No \\
12 UTC/15.05.2013 & $22.0 \%$ & Low & No \\
\hline
\end{tabular}

Table 4. Probability of rapid intensification (RI) for cyclone Phailin.

\begin{tabular}{lclc}
\hline Forecast based on & $\begin{array}{c}\text { Probability } \\
\text { of RI predicted }\end{array}$ & $\begin{array}{c}\text { Chances of } \\
\text { occurrence predicted }\end{array}$ & Occurrence \\
\hline 00 UTC/08.10.2013 & $9.4 \%$ & Very low & No \\
00 UTC/09.10.2013 & $9.4 \%$ & Very low & No \\
12 UTC/09.10.2013 & $9.4 \%$ & Very low & Yes \\
00 UTC/10.10.2013 & $72.7 \%$ & High & Yes \\
12 UTC/10.10.2013 & $72.7 \%$ & High & Yes \\
00 UTC/11.10.2013 & $72.7 \%$ & High & No \\
12 UTC/11.10.2013 & $32.0 \%$ & Moderate & No \\
\hline
\end{tabular}

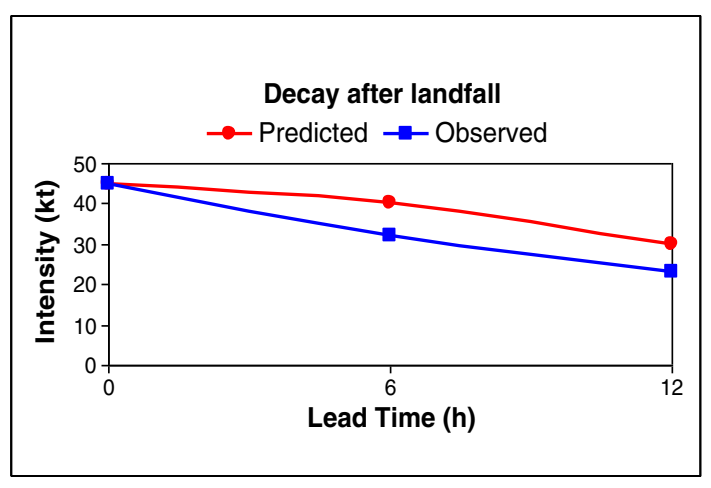

Figure 19. Decay after landfall by Decay model for cyclone Viyaru. predict the landfall point with significant accuracy, it predicted delayed landfall for cyclone Phailin for all forecast lead times, indicating slow movement prediction by MME in general. These aspects have to be further investigated and improved to provide greater spatial and temporal accuracy of forecasts. The purpose of this study was to assess the performance of CPS in real-time and also to provide operational forecasters the quantitative values of forecast errors for this technique for them to issue better guidance during real-time forecasting. Although primary results are encouraging, further study is required with more cases to get complete statistics and to assess the strength and weakness 

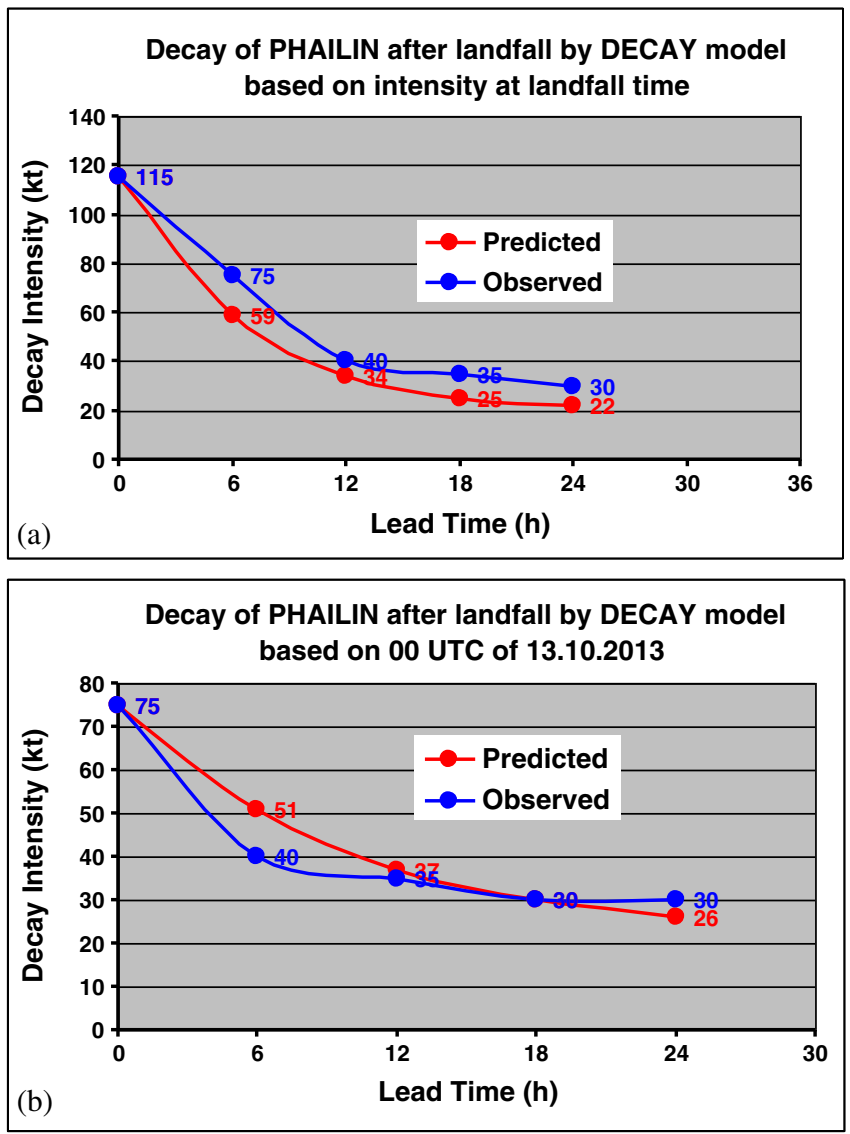

Figure 20. Decay after landfall by Decay model for cyclone Phalin. (a) Decay forecast based on landfall intensity and (b) decay forecast based on 00 UTC 13 October 2013.

of each component of CPS. Our future work will focus in that direction.

\section{Acknowledgements}

The authors are grateful to the Director General of Meteorology, India Meteorological Department, New Delhi for providing all the facilities to carry out this research work. Authors acknowledge the use of data from Cyclone Warning Division (IMD), ECMWF, NCEP, UKMO, and JMA in this study. Authors are grateful to the anonymous reviewers for their valuable comments which improved the quality of the paper.

\section{References}

DeMaria M and Kaplan J 1994 A Statistical Hurricane Intensity Prediction Scheme (SHIPS) for the Atlantic basin; Wea. Forecasting 9 209-220.

DeMaria M and Kaplan J 1999 An updated Statistical Hurricane Intensity Prediction Scheme (SHIPS) for the
Atlantic and east North Pacific basins; Wea. Forecasting $14326-337$.

DeMaria M, Mainelli M, Shay K L, Knaff A J and Kaplan J 2005 Further improvements to the Statistical Hurricane Intensity Prediction Scheme (SHIPS); Wea. Forecasting 20 531-543.

Fitzpatrick J P 1997 Understanding and forecasting tropical cyclone intensity change with the typhoon intensity prediction scheme (TIPS); Wea. Forecasting 12 826-846.

Elsberry R L, Lambert T D B and Boothe M A 2007 Accuracy of Atlantic and eastern North Pacific tropical cyclone intensity forecast guidance; Wea. Forecasting $\mathbf{2 2}$ $747-762$.

Goerss J S 2000 Tropical cyclone track forecasts using an ensemble of dynamical models; Mon. Wea. Rev. 128 1187-1193.

Houze R A, Chen S S, Smull B F, Lee W C and Bell M M 2007 Hurricane intensity and eyewall replacement; Science 315 1235-1238.

Krishnamurti T N, Kishtawal C M, LaRow T, Bachiochi D, Zhang Z, Williford C E, Gadgil S and Surendran S 1999 Improved skills for weather and seasonal climate forecasts from multimodel superensemble; Science $\mathbf{2 8 5}$ 1548-1550.

Krishnamurti T N, Kishtawal C M, Zhang Z, Larow T, Bachiochi D, Williford E, Gadgil $\mathrm{S}$ and Surendran S 2000 Multimodel superensemble forecasts for weather and seasonal climate; J. Climate 13 41964216.

Kaplan J and DeMaria M 1995 A simple model forpredicting the decay of tropical cyclone winds after landfall; J. Appl. Meteor. 34 2499-2512.

Kaplan J and Demaria M 2001 On the decay of tropical cyclone winds after landfall in the New England area; J. Appl. Meteor. 40 280-286.

Kalsi S R, Kotal S D and Roy Bhowmik S K 2003 Decaying nature of super cyclone of Orissa after landfall; Mausam 54 393-396.

Kotal S D and Bhattacharya S K 2013 Tropical cyclone genesis potential parameter (GPP) and its application over the North Indian Sea; Mausam 64149 170.

Kotal S D and Roy Bhowmik S K 2011 A Multimodel Ensemble (MME) technique for cyclone track prediction over the north Indian Sea; Geofizika 28 $275-291$.

Kotal S D and Roy Bhowmik S K 2013 Large-scale characteristics of rapidly intensifying tropical cyclones over the Bay of Bengal and a rapid intensification (RI) index; Mausam 64 13-24.

Kotal S D, Kundu P K and Roy Bhowmik S K 2009 Analysis of cyclogenesis parameter for developing and nondeveloping low pressure systems over the Indian Sea; Nat. Hazards 50 389-402.

Kotal S D, Roy Bhowmik S K, Kundu P K and Das A K 2008 A statistical cyclone intensity prediction (SCIP) model for Bay of Bengal; J. Earth Syst. Sci. 117 157168.

Kotal S D, Tyagi A and Roy Bhowmik S K 2012 Potential vorticity diagnosis of rapid intensification of very severe cyclone GIRI (2010) over the Bay of Bengal; Nat. Hazards $60461-484$.

Kotal S D, Bhattacharya S K, Roy Bhowmik S K and Kundu P K 2014 Growth of cyclone Viyaru and Phailin - a comparative study; J. Earth Syst. Sci. (this issue).

Mackey B P and Krishnamurti T N 2001 Ensemble forecast of a typhoon flood event; Wea. Forecasting 16 $399-415$. 
Roy Bhowmik S K, Kotal S D and Kalsi S R 2005 An empirical model for predicting decaying rate of tropical cyclone wind speed after landfall over Indian region; $J$. Appl. Meteor. 44 179-185.

Roy Bhowmik S K, Kotal S D and Kalsi S R 2007 Operational tropical cyclone intensity prediction - an empirical technique; Nat. Hazards 41 447-445.
Weber H C 2003 Hurricane track prediction using a statistical ensemble of numerical models; Mon. Wea Rev. 131 749-770.

Williford C E, Krishnamurti T N, Correa-Torres R J, Cocke S, Christidis Z and Vijaya Kumar T S 2003 Real-time multimodel superensemble forecasts of Atlantic tropical systems of 1999; Mon. Wea. Rev. 131 1878-1894. 